\title{
A responsabilidade social universitária e a avaliação institucional: reflexões iniciais
}

\author{
Enedina Betânia Leite de Lucena Pires Nunes \\ Isabel Cristina Auler Pereira \\ Maria José de Pinho
}

Resumo: As mudanças sociais geradas pela globalização, expansão da educação superior e desenvolvimento tecnológico estão demandando novas ações das universidades. Nesse contexto, a avaliação institucional, que compreende a autoavaliação e avaliação externa, assume papel de extrema importância para as instituições de ensino superior. Este artigo reflete sobre a dimensão da responsabilidade social universitária, abordada na avaliação das instituições de ensino superior instituída pela Lei 10.861 de abril de 2004 (SINAES). A inclusão da dimensão Responsabilidade Social no instrumento de avaliação interna e externa contribui para melhor conhecimento e evolução da instituição, para a formulação de políticas institucionais, além de colaborar para a melhoria do desenvolvimento institucional. O documento parte do pressuposto de que as ações sociais implementadas e oferecidas pelas instituições de ensino superior à comunidade em seu entorno são de extrema relevância não apenas por cumprirem dispositivos legais, mas por desencadearem um processo que reforçará a sua reponsabilidade social, contribuindo para a melhoria visando aferição da sua qualidade na formação das pessoas. A discussão teórica baseou-se em autores como Boaventura de Souza Santos (2011) e Dias Sobrinho (2008), o que permitiu refletir sobre a importância da ênfase no compromisso social da universidade. Trata-se de uma pesquisa qualitativa com levantamento bibliográfico e documental. Entende-se, portanto, que a universidade do século XXI precisa ser aberta e romper com o modelo tradicional de instituição, como um sistema fechado e lutar pela sua autonomia e legitimidade, no sentido de construir a sua identidade institucional e cumprir a sua responsabilidade social.

Palavras-chave: Universidade. Responsabilidade social. Autoavaliação institucional.

\section{University social responsibility and institutional evaluation: initial thoughts}

Abstract: The social changes generated by globalization, expansion of higher education and technological development are demanding new shares from universities. In this context, institutional evaluation, which includes the self-assessment and external evaluation, takes extremely important role for higher education institutions. This article reflects on the dimension of university social responsibility addressed in institutional evaluation of higher education institutions created by Law 10.861/2004 (SINAES). The inclusion of the social responsibility dimension into internal and external evaluation instrument may contribute to better knowledge and evolution of the institution, to formulate institutional policies and also contribute to the improvement of institutional development. The document starts from the assumption that the implemented social actions and offered by federal institutions of higher education to the community in its social environment are very important, not only to accomplish legal requirements, but also to be able to initiate a process of increasing its social responsibility, contributing to the improvement aimed at measuring the quality in training people. The theoretical discussion was based on authors such as Boaventura de Souza Santos (2011) and Dias Sobrinho (2008), which allowed reflecting on the importance of emphasis on the social commitment of the university. It is a qualitative research with documental and bibliographic survey. It is understood, therefore, that the University of XXI century needs to break the traditional model of institution, such as a closed system, and fight for its autonomy and legitimacy in order to build its institutional identity and fulfill its social responsibility.

Key words: University. Social responsibility. Institutional self-evaluation. 


\section{Introdução}

As mudanças sociais geradas pela globalização, expansão da educação superior e desenvolvimento tecnológico estão demandando novas ações das universidades. Nesse contexto, a avaliação institucional, que compreende a autoavaliação e avaliação externa, assume papel de extrema importância para as instituições de ensino superior.

Este artigo reflete sobre a dimensão da responsabilidade social universitária abordada no Instrumento de Avaliação Institucional Externa das instituições de ensino superior instituída pela Lei 10.861 de abril de 2004, que instituiu o Sistema Nacional de Avaliação da Educação Superior (SINAES). Refere-se à contribuição da Universidade em relação à "inclusão social, ao desenvolvimento econômico e social, à defesa do meio ambiente, da memória cultural, da produção artística e do patrimônio cultural", amparada nos princípios do SINAES como: compromisso e responsabilidade social das instituições de educação superior e de seus cursos; respeito à diversidade, à identidade, à missão, e a história das instituições; entre outros, assegurando que a avaliação institucional, interna e externa, contemple a análise global e integrada das dimensões, estruturas, relações, compromisso social, atividades, finalidades (BRASIL, 2004).

A partir dessa regulamentação, as instituições federais de ensino superior (IFES) devem definir no seu Plano de Desenvolvimento Institucional (PDI) a política institucional de responsabilidade social, delimitando as ações e programas a serem desenvolvidos, estabelecendo parâmetros para a referida política, previstos no Instrumento de Avaliação Institucional Externa, do Ministério da Educação (BRASIL, 2014a; 2014b).

Diante da grande expansão da educação superior por meio da ampliação de cursos e vagas de graduação e do combate à evasão, as instituições buscam formas de viabilizar, ampliar e melhorar as suas políticas institucionais, tais como investimentos na qualificação docente e na infraestrutura física e organizacional. Com vistas a garantir o acompanhamento e a melhoria do ensino, as IFES são submetidas ao processo de avaliação institucional. A inclusão da dimensão Responsabilidade Social no Instrumento de Avaliação Externa contribui para melhor conhecimento e evolução da instituição, para a formulação de políticas institucionais, além de colaborar para a melhoria do desenvolvimento institucional. $\mathrm{O}$ documento parte do pressuposto de que as ações sociais implementadas e oferecidas pelas instituições de ensino superior à comunidade em seu entorno são de extrema relevância não apenas por cumprirem dispositivos legais, mas por desencadearem um processo que reforçará a sua reponsabili- 
dade social, contribuindo para a melhoria visando aferição da sua qualidade na formação das pessoas.

A discussão teórica deste estudo baseou-se em autores como Santos (2011), o qual permitiu refletir sobre o reforço da responsabilidade social da universidade e as pressões globais exercidas sobre ela, Dias Sobrinho (2008), que discorre sobre a qualidade e sentido social e público de suas finalidades e objetivos; além da legislação educacional vigente aplicada pelo Ministério da Educação. A abordagem de pesquisa escolhida foi a qualitativa, com levantamento bibliográfico e documental, delineada pelo estudo da dimensão enfocada no Instrumento de Avaliação Institucional Externa à luz dos pressupostos teóricos e reflexões sobre o compromisso social da universidade.

\section{Fundamentos legais e teóricos da responsabilidade social nas universidades}

A educação é assegurada pela Constituição Federal de 1988, em seu Art. 205, como: "A educação, direito de todos e dever do Estado e da família, será promovida e incentivada com a colaboração da sociedade, visando ao pleno desenvolvimento da pessoa, seu preparo para o exercício da cidadania e sua qualificação para o trabalho" (BRASIL, 1988, p. 69). Para garantir este direito, a Constituição Federal declara no Art. 206:

Art. 206. O ensino será ministrado com base nos seguintes princípios: I - igualdade de condições para acesso e permanência na escola; II - liberdade de aprender, ensinar, pesquisar e divulgar o pensamento, a arte e o saber;

III - pluralismo de ideias e de concepções pedagógicas, e coexistência de instituições públicas e privadas de ensino;

IV- gratuidade do ensino público em estabelecimentos oficiais;

$\mathrm{V}$ - valorização dos profissionais do ensino, garantidos na forma da lei, planos de carreira para o magistério público, piso salarial profissional e ingresso exclusivamente por concurso público de prova e títulos; VI - gestão democrática do ensino público, na forma da lei;

VII - garantia de padrão de qualidade (BRASIL, 1988, p. 69).

A Constituição Federal estabelece o princípio da autonomia universitária em seu artigo 207 que evidencia a questão central relacionada ao conceito de responsabilidade social aplicado às instituições educacionais: "As universidades gozam de autonomia didático-científica, administrativa e de gestão financeira patrimonial, e obedecerão ao princípio de indissociabilidade entre ensino, pesquisa e extensão" (BRASIL, 1988). 
Santos (2011, p. 65) reforça o princípio da indissociabilidade entre ensino, pesquisa e extensão ao afirmar que "[...] no século XXI só há universidade quando há formação graduada e pós-graduada, pesquisa e extensão. Sem qualquer destes, há ensino superior, não há universidade”. Esse posicionamento está consoante com os pressupostos da Lei de Diretrizes e Bases da Educação Nacional (LDB), que em seu art. 52 deixa claro que

\begin{abstract}
Art. $52^{\circ}$. As universidades são instituições pluridisciplinares de formação dos quadros profissionais de nível superior, de pesquisa, de extensão e de domínio e cultivo do saber humano, que se caracterizam por:

I - produção intelectual institucionalizada mediante o estudo sistemático dos temas e problemas mais relevantes, tanto do ponto de vista científico e cultural, quanto regional e nacional. [...] (BRASIL, 1996, p. 18-19).
\end{abstract}

Pensando sobre as transformações e mudanças na relação entre a universidade e a sociedade, no artigo "Por uma universidade socialmente relevante", Mello, Almeida Filho e Ribeiro (2009) apontam para o triplo desafio da Universidade Pública brasileira: o padrão de qualidade; a universalidade de acesso a todos e a todas que demonstrarem vocação, aptidão e motivação e o desenvolvimento de programas sociais relevantes capazes de contribuir para a solução de problemas. Ressaltam que esses desafios devem estar alinhados à missão da universidade pública num contexto globalizado, econômico, social e democrático, o que a torna "paradigma ético para o mundo" (MELLO; ALMEIDA FILHO; RIBEIRO, 2009, p. 293). Complementando afirmam que:

Se uma universidade europeia ou norte-americana pode dar-se ao luxo de exibir, como principal distintivo, a pertinência científica - já que as ações sociais e as iniciativas de inovação tecnológica são assumidas pela forte e atuante sociedade civil ali presente -, a universidade brasileira precisa demonstrar, além da qualidade acadêmico-científica e sem renunciar a ela, relevância social (p. 294).

Ao se discutir a responsabilidade social universitária parte-se do pressuposto de que as universidades têm autonomia didático-científica, administrativa, financeira e patrimonial conquistada historicamente. Contudo, por ela estar vinculada aos órgãos governamentais, essa autonomia, de certa forma, torna-se parcial face às regulamentações nem sempre adequadas ao cumprimento de sua missão. Desta forma, seria contraditório, falar de responsabilidade social da universidade sem autonomia. Esta contradição se apresenta em meio às três 
crises anunciadas por Santos (2011), nos últimos vinte anos: de hegemonia, de legitimidade e institucional. A crise de hegemonia resulta de funções sociais contraditórias da universidade, uma vez que, além de produtora da alta cultura e formadora das elites desde os tempos da Idade Média, é também produtora de padrões culturais médios e de conhecimentos instrumentais, para formar mão-de-obra qualificada. A incapacidade de a universidade desempenhar plenamente essas duas funções teria levado os agentes econômicos a privilegiar meios alternativos fora da universidade. A crise de legitimidade, por sua vez, foi provocada pelo fato de a instituição universitária ter deixado de ser consensual devido a contradição entre a hierarquização dos saberes especializados, assim como pelas exigências sociais e políticas de democratização das universidades e reivindicações de igualdade de oportunidades para os filhos das classes populares. Finalmente, ocorreu também uma crise institucional resultante da contradição entre a reivindicação de autonomia universitária pela definição dos seus valores e objetivos e a pressão para a submissão da universidade a critérios de eficácia e produtividade de natureza empresarial ou de responsabilidade social.

Neste processo, Santos (2011) apresenta cinco fatores para reconquistar a legitimidade da universidade em cinco áreas de ação: acesso; extensão; pesquisa-ação; ecologia de saberes; universidade e escola pública. A democratização do acesso deve ser sem discriminação de classe, raça, sexo ou etnia para garantir a permanência dos estudantes de classes sociais discriminadas, mas associando-se à área de extensão por meio de programas destinados a grupos sociais, movimentos sociais, comunidades locais e regionais; governos locais e os setores público e privado, de forma a evitar atividades de rentabilidade extra-orçamentária e buscando apoio solidário para solução da exclusão e da discriminação social. Outra área de ação é a pesquisa-ação que atua integrando extensão, pesquisa e ensino e consiste na execução e elaboração de projetos de pesquisa, envolvendo a comunidade e promovendo o que o autor chama de ecologia de saberes. Trata-se de "uma forma de extensão ao contrário" (SANTOS, 2011, p. 75), da abertura da universidade de fora para dentro, de maneira a promover o diálogo entre saber científico, produzido pela universidade, com os múltiplos saberes populares produzidos na sociedade. Finalmente, na área de ação universidade e escola pública, é preciso que se reestabeleça a ligação com a educação básica, sobretudo no que diz respeito à formação de docentes.

Reconhece-se que a partir disto, o que o autor propõe é um programa de responsabilização social da universidade, pois, somente por meio dele, poderá lutar pela sua legitimidade, mas, para que isso ocorra, a universidade tem que ser dotada das condições adequadas tanto financeiras como institucionais. 
A responsabilidade social de uma instituição educativa, segundo Dias Sobrinho (2008, p. 195), diz respeito "ao cumprimento, com qualidade e sentido social e público, de suas finalidades e seus objetivos essenciais: a formação [...], valores, [...] a solidariedade, a liberdade, a justiça, os direitos públicos, o respeito à diversidade[...]".

Neste cenário, a responsabilidade social da universidade tem como capacidade definir seu próprio destino em meio às incertezas e desafios. Assim, a avaliação institucional interna (autoavaliação) torna-se uma atividade de fundamental importância. Entretanto, mediante as políticas de avaliação externa regulada pelo SINAES, a universidade passa por avaliações periódicas pelas comissões designadas pelo Ministério da Educação, caracterizando a situação de dependência e autonomia relativa das instituições públicas de ensino superior.

\section{0 indicador de qualidade no instrumento de avaliação institucional externa}

O Instrumento de Avaliação Institucional Externa, revisado e atualizado em agosto de 2014, pelo Ministério da Educação, subsidia os atos de credenciamento, recredenciamento e transformação da organização acadêmica (presencial). Está organizado em cinco eixos que contemplam as dez dimensões do SINAES. Dentre esses dez eixos, o Eixo 2 refere-se ao Desenvolvimento Institucional e contempla as dimensões 1 (Missão e Plano de Desenvolvimento Institucional) e 3 (Responsabilidade Social da Instituição) do SINAES (BRASIL, 2004, 2014a 2014b). Os itens a serem avaliados nessas duas dimensões potencializam a importância da responsabilidade social relacionando-a ao ensino, pesquisa, extensão e gestão, considerando a indissociabilidade entre estes segmentos.

A dimensão da Responsabilidade Social, discutida neste artigo, está contemplada no eixo de Desenvolvimento Institucional. Esta dimensão é considerada especialmente no que se refere à sua contribuição em relação à inclusão social, ao desenvolvimento econômico e social, à defesa do meio ambiente, da memória cultural, da produção artística e do patrimônio cultural, e ações afirmativas de defesa e promoção dos direitos humanos e igualdade étnico- racial.

É evidente que se as instituições se limitarem ao referencial mínimo legal exigido para que se obtenha conceito suficiente em sua avaliação institucional externa, a sua atuação no campo da responsabilidade social será estritamente dentro dos parâmetros avaliativos do SINAES. Desse modo, ao elaborar o Plano de Desenvolvimento Institucional (PDI), a instituição deve definir sua visão de responsabilidade social, delimitando na sua política institucional e as ações e 
programas a serem desenvolvidos, sendo recomendável que, em seu programa de avaliação institucional, estejam definidos os indicadores de responsabilidade social na condução da referida política.

Neste sentido, na avaliação institucional externa, esta dimensão apresenta indicadores que ao serem aplicados deverão ser verificados trabalhos, ações, atividades, projetos e programas desenvolvidos com e para a comunidade, objetivando a inclusão social, o desenvolvimento econômico, a melhoria da qualidade de vida, da infraestrutura urbana/local e a inovação social. Desta forma, percebe-se que o instrumento de avaliação evidencia indicadores com critérios de análise subjetivos, porém, as instituições são levadas a organizar as informações e os documentos para atender de forma objetiva os indicadores.

Com relação às ações institucionais nas suas vertentes de ensino, pesquisa e extensão, o instrumento considera as atividades de ensino de graduação e de pós-graduação, as práticas de extensão e as atividades de pesquisa/iniciação científica, tecnológica, artística e cultural, de forma que haja coerência entre o Plano de Desenvolvimento Institucional (PDI) e as atividades implantadas considerando que a responsabilidade social está incorporada em todas as vertentes.

Por meio da Portaria $n^{\circ}$ 92, de 31 de janeiro de 2014, o Ministério da Educação (BRASIL, 2014a) estabeleceu os indicadores dos eixos das dimensões do SINAES do Instrumento de Avaliação Externa (BRASIL, 2014b), aplicado pelas comissões de avaliação in loco. O Eixo 2 do Instrumento foca no Plano de Desenvolvimento Institucional (PDI) e leva em consideração as ações afirmativas desenvolvidas pela instituição no contexto de sua inserção social, tomando como base à missão institucional, as metas e os objetivos do PDI. Contempla indicadores de Responsabilidade Social da Instituição, destacando-se os seguintes:

2.5 Coerência entre o PDI e as ações institucionais no que se refere à diversidade, ao meio ambiente, à memória cultural, à produção artística e ao patrimônio cultural.

2.6 Coerência entre o PDI e ações de responsabilidade social: inclusão social.

2.7 Coerência entre o PDI e ações afirmativas de defesa e promoção dos direitos humanos e igualdade étnico- racial. (BRASIL, 2014b, 8-10).

Observa-se pelo exposto, o estabelecimento de ações de incentivo que fazem com que as instituições busquem mostrar por meio de práticas sociais a sua contribuição junto à sociedade, demonstrando o seu compromisso e, consequentemente, a sua responsabilidade social. 


\section{A responsabilidade social na extensão universitária}

As grandes transformações e mudanças sociais trazidas pela globalização e pelos avanços das tecnologias de informação e comunicação exigem das instituições de educação superior a formação do cidadão com responsabilidade e ética. Assim, o ensino, a pesquisa e a extensão são atividades acadêmicas voltadas para a sociedade e para o desenvolvimento do cidadão, pois como afirma Santos (2011, p. 113), “A universidade é um bem público intimamente ligado ao projeto de país".

Nas universidades, a responsabilidade social está atrelada normalmente à extensão universitária, considerada a sua relação com a sociedade juntamente com os demais segmentos ensino e pesquisa. Porém, a concepção de responsabilidade social não deve estar voltada somente às ações específicas de extensão, tendo em vista que o processo educacional é sistêmico e indissociável. A extensão é definida no Instrumento de Avaliação Externa como "Processo interdisciplinar educativo, cultural, científico e político, sob o princípio constitucional da indissociabilidade entre ensino e pesquisa, que promove a interação transformadora entre a IES e outros setores da sociedade" (BRASIL, 2014b, p. 33).

Nessa perspectiva, Santos (2011, p. 73) afirma que

a reforma da universidade deve conferir uma nova centralidade às atividades de extensão" atribuindo-lhe "uma participação ativa na construção da coesão social, no aprofundamento da democracia, na luta contra a exclusão social e a degradação ambiental, na defesa da diversidade cultural.

A extensão universitária está caracterizada no Instrumento de Avaliação Externa, envolvendo diferentes dimensões e contemplando os seguintes indicadores de avaliação: a coerência entre o PDI e as práticas de extensão; as ações acadêmico-administrativas de extensão considerando o apoio à realização de programas, projetos, atividades e ações; os canais de comunicação externa e interna considerando o acesso da comunidade externa e interna às informações acerca dos resultados das avaliações recentes, da divulgação dos cursos, da extensão e pesquisa, da existência de mecanismos de transparência institucional, da ouvidoria, entre outros; as fontes de recursos previstas/executadas para o custeio e aos investimentos em ensino, extensão, pesquisa e gestão; o planejamento financeiro (orçamento com as respectivas dotações e rubricas) previsto/executado relacionado com a gestão do ensino, da pesquisa e da extensão (BRASIL, 2014b). 
Considerando que estes indicadores atendem à dimensão responsabilidade social como elementos da avaliação do SINAES, não se pode, portanto, tratar a responsabilidade social em paralelo na avaliação institucional. O tratamento assistencialista dado à extensão deve ser eliminado por ter esta uma posição estratégica nas atividades de ensino, pesquisa e administrativa desenvolvidas pela universidade. Segundo Vallaeys (2006, p. 38),

a universidade precisa tratar de superar o enfoque da "projeção social e extensão universitária" como "apêndices" bem intencionados de sua função central de formação estudantil e produção de conhecimentos, a fim de poder atender ao que de fato está a exigir a Responsabilidade Social Universitária.

A universidade como um bem público, embora seja influenciada por um modelo de avaliação regulado pelo órgão governamental deve destacar-se pela sua responsabilidade social considerando a sua contribuição nos aspectos sociais, culturais, ambientais, econômicos. Com a implantação do Sistema Nacional de Avaliação da Educação Superior (SINAES), em 2004, a discussão sobre a Responsabilidade Social estendeu-se às Instituições de Ensino Superior (IES) que passaram a contar com esse marco regulatório estabelecendo os critérios de avaliação da Responsabilidade Social, a terceira dimensão do SINAES. Estrutura-se em aspectos discorridos a seguir:

\section{a) A defesa do meio ambiente, da memória cultural, da produção artística e do patrimônio cultural.}

Um dos objetivos da universidade é a produção do conhecimento no que concerne a sua contribuição para o desenvolvimento cultural, por meio de ações que promovam os direitos humanos, a educação, a cultura, a saúde, o trabalho, as tecnologias, o meio ambiente, a comunicação; com atenção especial para as populações em condições de vulnerabilidade, considerando a diversidade de gênero, raça, credo, idade e etnia. Neste contexto, as atividades de extensão voltadas para a promoção da arte e cultura destinadas às demandas do entorno social e cultural articulando os conhecimentos e os currículos deverão estar apoiados e difundidos nas diversas manifestações culturais advindas das demandas da comunidade acadêmica.

Estas ações poderão ser fortalecidas na relação, por exemplo, com cursos na área de Artes, Teatro, Educação do Campo, Música, entre outros, valorizando tanto o saber das atividades acadêmicas de ensino, pesquisa e extensão quanto os saberes populares. Neste sentido, ações pontuais podem ser fomentadas, 
por meio de práticas dentro do ambiente acadêmico, resultando em produtos culturais, por exemplo, em uma peça teatral, show musical, entre outros.

Existem também os programas e projetos universitários que visam à sensibilização e à tomada de consciência da comunidade sobre o valor dos ecossistemas, realidade ambiental e participação no processo de preservação dos recursos naturais, no sentido de promover reflexões que sirvam de estímulo e interesse pela questão ambiental.

\section{b) A inclusão social}

As ações desenvolvidas como programas e projetos seguem critérios que visam um acesso democrático à Universidade. Dentre as ações desenvolvidas, destaca-se especialmente o Programa Centro de Referência em Cidadania e Direitos Humanos, aprovado pelo Edital Nacional do Ministério da Educação, está incluído na linha temática Direitos Humanos, do Programa de Extensão Universitária MEC/SESu. A proposta prevê ações mediadoras com instituições parceiras que garantam o atendimento jurídico e psicológico, sendo o atendimento social e antropológico efetuado pelos docentes participantes do Programa, com o intuito de instrumentalizar os indivíduos atendidos para que reivindiquem seus direitos e que possam conquistar a autonomia. O programa tem como meta superar a mera prestação de serviços à comunidade, proporcionando o desenvolvimento de um Programa que se relacione com a investigação científica e com a produção de conhecimentos voltados para a qualificação do ensino a partir da realidade sociocultural, missão e valores da instituição de ensino superior.

Há também programas nas universidades que se propõem a capacitar professores e gestores para o uso pedagógico das tecnologias digitais de informação e comunicação (TDIC), com a finalidade de possibilitar a inclusão digital escolar e a apropriação tecnológica e pedagógica dessas tecnologias.

\section{c) $\mathrm{O}$ desenvolvimento econômico e social}

A responsabilidade social universitária considerando a sua contribuição para o desenvolvimento econômico em articulação com os setores produtivos da sociedade pode contribuir para o fortalecimento da extensão universitária. Neste sentido, muitas universidades implantaram programas que se referem ao comprometimento da universidade com a reparação das distorções histórias que afastam a maior parte da população brasileira da graduação em instituições públicas de ensino, onde incialmente preparam os candidatos com perfis de vulnerabilidade socioeconômica para que posteriormente eles possam ingressar 
na universidade. Por meio de relações com os setores produtivos, a Universidade toma conhecimento dos problemas, desafios e interesses econômicos direcionando seus esforços para contribuir com soluções para o desenvolvimento econômico regional e nacional. Entre os setores produtivos, destacam-se aqueles comprometidos com a economia solidária e tecnologias sociais.

A Política Nacional de Extensão Universitária (2012), reafirma a Extensão Universitária como:

o mecanismo por meio do qual se estabelece a inter-relação da Universidade com os outros setores da sociedade, com vistas a uma atuação transformadora, voltada para os interesses e necessidades da maioria da população e propiciadora do desenvolvimento social e regional, assim como para o aprimoramento das políticas públicas (FORPROEX, 2012, p. 20).

Desta forma, as políticas de extensão e cultura devem enfatizar o papel da extensão articulada com o ensino e a pesquisa de forma indissociável, de viabilizar a relação transformadora entre a universidade e a sociedade, estabelecendo o vínculo entre o conhecimento acadêmico, a intervenção social e o comprometimento com o desenvolvimento sociocultural da comunidade.

\section{Reflexões finais}

A responsabilidade social universitária é uma dimensão que relaciona vários aspectos quanto aos conhecimentos produzidos e difundidos na universidade que variam de acordo com o seu contexto social, promovendo ações com base em princípios éticos que asseguram o desenvolvimento considerando a sua contribuição no âmbito social, cultural, ambiental e econômico. Assim, a responsabilidade social universitária é discutida como um compromisso social e educacional da universidade com a igualdade social, meio ambiente, direitos humanos, ciência e a tecnologia, entre outros.

Entende-se, portanto, que a universidade do século XXI precisa ser aberta e romper com o modelo tradicional de instituição, como um sistema fechado, e lutar pela sua autonomia e legitimidade, no sentido de construir a sua identidade institucional e cumprir a sua responsabilidade social.

O SINAES avalia a responsabilidade social tendo como foco a inclusão social, o desenvolvimento econômico e social, a defesa do meio ambiente, a memória cultural, a produção artística e o patrimônio cultural, o que leva as instituições de ensino superior a promoverem ações sociais relacionadas 
ao ensino, pesquisa, extensão e gestão, em uma análise sistêmica e global. A responsabilidade social universitária na avaliação institucional representa um reforço para a sociedade por ser a universidade o lugar de elevada produção e formação de seus cidadãos para a vida e para o mercado de trabalho, influenciando nas suas condições de vida, oferecendo um retorno à sociedade produzindo conhecimentos diversos, próprio de um lócus reflexivo, crítico e inventivo, que garanta uma docência da educação superior com capacidade para formar sujeitos socialmente e politicamente comprometidos e motivados pelo conhecimento.

\section{Referências}

BRASIL. Constituição da República Federativa do Brasil (1988).

Brasília, DF: Senado, 1988. Disponível em. <http://www.planalto.gov.br/ ccivil_03/constituicao/constituicaocompilado.htm>. Acesso em: 28 mai. 2015.

BRASIL. Lei de Diretrizes e Bases da Educação Nacional. Lei no ${ }^{\circ}$ 9.394, de 20 de dezembro de 1996. Estabelece as diretrizes e bases da educação nacional. Disponível em: <http://portal.mec.gov.br/arquivos/pdf/ldb.pdf.>. Acesso em: 31 mai. 2015.

BRASIL. Lei $\mathbf{N}^{\mathbf{0}} \mathbf{1 0 . 8 6 1}$, de 14 de abril de 2004. Institui o Sistema Nacional de Avaliação da Educação Superior - SINAES e dá outras providências. Disponível em: <http:/www.planalto.gov.br/ccivil_03/_ato2004-2006/2004/ lei/110.861.htm>. Acesso em: 28 maio 2015.

BRASIL. Ministério da Educação. Portaria no 92, de 31 de janeiro de 2014. Aprova, em extrato, os indicadores do Instrumento de Avaliação Institucional Externa para os atos de credenciamento, recredenciamento e transformação de organização acadêmica, modalidade presencial, do Sistema Nacional de Avaliação da Educação Superior - SINAES. Diário Oficial [da] República Federativa do Brasil, Brasília, DF, seção 1, p. 5, 4 fev. 2014a.

BRASIL. Ministério da Educação. Comissão Nacional de Avaliação da Educação Superior (CONAES). INEP. SINAES. Instrumento de Avaliação

Institucional Externa. 2014b. Subsidia os atos de credenciamento, recredenciamento e transformação da organização acadêmica (presencial). 
Disponível em: < http://download.inep.gov.br/educacao_superior/avaliacao_ institucional/instrumentos/2015/instrumento_institucional_072015.pdf $>$. Acesso em: 28 mai. 2015.

DIAS SOBRINHO, José. Avaliação educativa: produção de sentidos com valor de formação. Avaliação, Campinas; Sorocaba, SP, v. 13, n. 1, p. 193207, mar. 2008.

FORPROEX. Fórum de Pró-Reitores de Extensão das Universidades Públicas Brasileiras. Política Nacional de Extensão Universitária. Manaus, 2012.

MELLO, Alex F. de; ALMEIDA FILHO, Naomar; RIBEIRO, Renato Janine. Por uma Universidade Socialmente Relevante. Atos de Pesquisa em Educação - Programa de Pós-Graduação em Educação/FURB, Blumenau, v. 4, n. 3, p. 292-302, set./dez. 2009.

SANTOS, Boaventura de S. A universidade no século XXI: para uma reforma democrática e emancipatória da Universidade. 3. ed. São Paulo: Cortez, 2011. (Coleção questões da nossa época; v. 11).

VALLAEYS, François. Que Significa Responsabilidade Social Universitária? Revista da Associação Brasileira de Mantenedoras de Ensino Superior, Brasília, v. 24, n. 36, p. 38-55, jun. 2006.

Enedina Betânia Leite de Lucena Pires Nunes - Universidade Federal do Tocantins Palmas | TO | Brasil. Contato: enedina@uft.edu.br Isabel Cristina Auler Pereira - Universidade Federal do Tocantins Palmas | TO | Brasil. Contato: isabel@uft.edu.br Maria José de Pinho - Universidade Federal do Tocantins Palmas | TO | Brasil. Contato: mjpgon@uft.edu.br e aprovado em 21 de dezembro de 2015. 
